\title{
Carbon Accounting, Green Building and Sustainability: Effects on Gross National Product (GDP)
}

\author{
Munshi Samaduzzaman, ${ }^{1}$ Fazluz Zaman, ${ }^{2}$ Munshi Shamsuzzaman $\operatorname{Irfan}^{3}$ \\ ${ }^{1,}$ Adjunct lecturer, University of Liberal Arts Bangladesh, Dhaka, Bangladesh \\ ${ }^{2}$, Adjunct lecturer, University of New South Wales, Sydney, Australia \\ 3. Adjunct lecturer, Academies Australasia, Sydney, Australia
}

\begin{abstract}
Carbon and greenhouse gas emissions are among the major environmental problems in Bangladesh, India and Australia. Due to various sources, pollutants in the air put the residents, particularly the children to serious health risks. Gathered measurement data had revealed that carbon and greenhouse gas emissions in some cities of the said countries had reached undesirable levels and now affecting the country's gross domestic product (GDP). To resolve this, various organizations considers carbon accounting and had developed relevant programs and policies that will help minimize carbon and greenhouse gas emissions in the state. In this brief discussion, major pollutants in Bangladesh, India and Australia and some of their cities were discussed. From their efforts, this paper identified that awareness not only for carbon accounting but also the effect of climate change has brought about a drastic, rethink of the way buildings are now designed and run, and with the governments, initiatives to drastically lower greenhouse gas emissions, sustainability has taken a better role in the built environment and of course to the country's GDP. Furthermore, different programs and efforts done to reduce carbon and greenhouse gas emissions in the state were cited as well.
\end{abstract}

\section{Introduction}

Sustainable development is one of the issues mostly discussed in the current era. In accordance to this, a lot of people and government agencies are creating expressive efforts towards the issues relating to carbon emission, green house effects, and global warming. In Bangladesh, India and Australia, the context or the idea known as "carbon accounting" was prevalent not only due to the needs of creating sustainable environment but also its roles and impact played in the country's Gross Domestic Product (GDP).

\section{Discussion}

In the current era, global issues pertaining to the measurement of carbon and greenhouse gas emissions creates crucial impact to the country's total economic progress which are most likely reflecting to their GDPs. For instance, in India, the country has various significant efforts in measuring carbon footprints, whereas the total greenhouse gas emissions caused directly and indirectly by an individual, event, organization or product has been considered (Pearce, 2003). In India, "Carbon Accounting" is also called GHG accounting which assesses the carbon footprint. This effort helps various organisations adopt strategies aimed at countering the effects of climate change (Tol, 2003). Similar to the usual accounting practices in businesses, carbon accounting also follow these rules to ensure that fair and correct measurement of carbon exiting in an area or certain locations are correct (Pearce, 2003). These practices also guarantee that the reported information is true, fair and reliable.

In accordance to this, business organisations in India initiated various public forums that details significant carbon accounting and reporting. The known forums in India include Carbon Disclosure Project (CDP) and the company's Sustainable Development Reports (Pearce, 2003).

India as one of the poor nations is more vulnerable to the effects of carbon accounting efforts both on its scientific and economic perspective (Tol, 2003). Economically speaking, India has limited resources of revenue which are affecting their GDP. Their economic stratum is distant lower as to compare to richer nations. Basically, India is more centered on the aspect of production of food and industry to maintain the survival of their economy. But due to the effects of this existing phenomenon wherein richer countries contribute greatly to its spreading out, it is no longer important for the developing countries to allocate budget for precautionary measures and standards. In accordance to India's GDP, carbon accounting efforts and due to lack of capability to spend money for new trends of technology, the acquisition of modern means of technology to help them predict and lessen the effects of the situation is relatively impossible (Tol, 2003).

On the other hand, in Bangladesh agriculture, which is their main source of revenue, is greatly and primarily affected by carbon emission present in their country (Ali, 2002). The increase temperature of the weather is very much hazardous to the growth of crops and other vegetations. The effects will surely damaged the production process of every agricultural industry especially farming and plant propagation. Its effects in the 
production will entirely change the flow of income to every working community (Marland, Fruit, \& Sedjo, 2001). In China, there was a decrease in the harvest of agricultural product due to the costliest disaster of 1998 and at the same time flooding killed more than 3,000 people. The Yangtze basin has lost 85 percent of its woods to logging and agricultural industry" (Johansen, 2002). In the same source, "two-thirds of Bangladesh, which is situated at the mouths of the Ganges and Brahmaputra Rivers, was swamped for several months during 1998, as 30 million inhabitants were left temporarily homeless. Another effect to the environment is animal waste that contains methane gas and responsible global warming.

In Australia, modern agricultural advancements are some possible resolution to counter carbon emission issues (Polglase \& Richards, 2002 and Paul, et al. 2001). Cline (1992) predicted unwanted technological changes and improvements that could reduce the extent of damages from such phenomenon. The agricultural industry of a country is one of his focuses. For instance, through the development of miracle seed varieties resistant to drought (Cline, 1992), the problem of agricultural depression in food production will be greatly improve and might be a possible outlet for an opening of world trade for food exportation. It therefore creates a big source of revenue for the host country at the same time surviving the drought and saving its people from hunger. However, Cline (1992) also argued that, "there is no reason to expect unforeseen technological breakthroughs to reduce greenhouse damages and the corresponding benefits of abatement policy action by more (or less) than they reduce the costs of action (p.84)." Still, the phenomenon of global warming is still left as a big natural predicament.

According to (BBC News, 2007):

"The panel's chairman, Rajendra Pachauri, highlighted the need to deal with impacts which are coming whether or not global emissions are curbed. Even if levels of $\mathrm{CO}_{2}$ in the atmosphere stayed where they are now, he said research showed sea levels would rise by between 0.4 and 1.4 metres simply because sea water would continue warming up, which makes it expand."

Basically, the issues of $\mathrm{CO}_{2}$ emission and efforts towards carbon accounting are not the efforts only present in India, Bangladesh and Australia, but it is also present in other countries. Aside from this, countries are also employing various actions and not only carbon accounting, and these includes, establishments of laws/bills relating to $\mathrm{CO}_{2}$ emissions and building codes relating to sustainable building. For instance, there is a widespread flooding that has occurred in the South East of the UK that undoubtedly will occur again if the levels of $\mathrm{CO}_{2}$ in the environment aren't dramatically lowered.

Aside from considering carbon accounting, there have been measures taken to reduce current $\mathrm{CO}_{2}$ emissions released into the atmosphere via legislations and bills relating to the matter. The climate change bill (No 45 of 2005) "aims to combat climate change by setting annual targets for the reduction of carbon dioxide emissions until 2050 and to place duties on the prime minister regarding the reporting on, and achievements of, those targets." (Hall, 2006).

The energy bill (No 129 of 2005-06) seeks to establish a renewable energy authority, and to lay upon the authority a duty to promote the use of renewable energy and energy conservation (Hall, 2006). Though there have been measures taken to reduce mans carbon footprint on the environment, further measures need to be taken to sustain the way in which we live for ourselves and future generations. With the construction industry contributing largely to the destructive impact on the environment, it is clear that "less energy intensive" means of producing construction materials needs to be adhered to, while providing long lasting sustainable construction methods.

Snell \& Callahan, (2005) provides an insightful look at "Low Construction Impact" stating that:

"Building, almost by definition, is initially a destructive act. Land usually has to be at least minimally cleared and reshaped, holes need to be dug, and material resources refashioned to serve the building. A "green" building minimises its impact on the building site and the environment at large through careful, conscious design, and by utilising replenishable materials that create a minimum of ecological destruction through their use."

Even though the statement rains true, with respect to sustainable buildings, it is not always followed and if followed only to a certain degree. This in the author's opinion is all too common, with little scope being ascertained on several of the issues governing the construction of a sustainable building, the post mining sustainable redevelopment of inland Cornwall, is one such project that does not entirely follow the rules of sustainability. The sustainable construction project is sound promising, but what of the materials used in the construction. Are they renewable? Do they carry large quantities of embodied energy? And are the materials used "Low emission materials" that help in the reduction of $\mathrm{CO}_{2}$ emissions?

Despite many buildings start off life with a strong will to be sustainable, in reality this is not true, with many buildings generating two or even three times as much $\mathrm{CO}_{2}$ as firstly predicted (Bordass, 2001). A "Cradleto-grave" strategy often referred to as "Cradle-to-cradle" approach, highlights the enormous extraction of all materials being used in today's built environment, this will lead to a devastating waste disposal programme in the future, and will subsequently lead to further massive amounts of $\mathrm{CO}_{2}$ being emitted into an already fragile environment (Kibert, 2007). 
Yamaguchi, Matsufuji \& Koyama, (2007) further sympathises with the above statement, by adding that:

"The key concepts 'reduce', 'reuse' and 'recycled' have been said to be effective in minimising environmental damage, and the effect of reuse in particular is high because the processing required for recycling, in which the material is remanufactured, can be eliminated, providing a considerable reduction in environmental load."

This further reiterates that if buildings were constructed, with "disassembly" in mined key emissions given off through waste, and transportation could be drastically reduced (Yamaguchi, Matsufuji \& Koyama, 2007). However, the issue of "Embodied Energy" is influential when designing and constructing a sustainable building.

Hall, (2006) defines embodied energy as, "The energy required to produce a material, through extraction, manufacture, transport or installation." This is a key issue in particular with the "Castle Meadow" Inland Revenue building in Nottingham, as "low energy intensive" materials could give off as much $\mathrm{CO}_{2}$ as "high energy intensive" materials if they carry substantial amounts of embodied energy.

In Bangladesh, India and Australia, carbon accounting was actually concerned with regards to climate change and of course to the country's GDP. Actually, the full affects of climate change are still being researched by scientists all over the world, but it is clear that the environment is no longer what it used to be a millennium ago. McCann, (2004) states that "What is understood and accepted by the majority of the scientific community is that the emissions of greenhouse gases from human activities are driving the process of climate change".

It's widely understood that mans greatest contribution to global warming is brought about by the burning of fossil fuels, which in turn has resulted in billions of tonnes of $\mathrm{CO}_{2}$ being released into the environment. The results can already be seen as eleven of the last twelve years dating from 1995 to 2006 have ranked as the warmest years in the instrumental record (CIBSE, 2007).

According to Smith, (2006):

"Global temperature is now increasing at $0.17^{\circ} \mathrm{C}$ per decade, and is projected by the IPPC to be between 1.4 and $5.8^{\circ} \mathrm{C}$ above 1990 levels in 2100 . Sea levels could be between 9 and 88 centimetres above 1990 levels by 2100 . As temperature continues to increase the frequency of drought and extreme rainfalls are also expected to increase with a wide range of impacts on both the natural environment and human society."

It's clear that the state of the climate will only get worse, if the future and current $\mathrm{CO}_{2}$ emissions are not cut down. Greenhouse gas emissions have increased since the pre-industrial times, with around $70 \%$ being contributed between 1970 and 2004 (CIBSE, 2007). This in turn has caused several of the world's problems ranging from changing rainfall patterns, glaciers melting, sea levels and violent weather storms taken place all over the world (Defra 2006).

CIBSE, (2007) states that:

"Global increases in $\mathrm{CO}_{2}$ concentrations are due primarily to fossil fuel use, with land use change providing another significant but smaller contribution. It is very likely that the observed increase in $\mathrm{CH}_{4}$ concentration is predominantly due to agriculture and fossil fuel use. Methane growth rates have declined since the early 1990s, consistent with total emission (sum of anthropogenic and natural sources) being nearly constant during the period. The increase in $\mathrm{N}_{2} \mathrm{O}$ concentration is primarily due to agriculture.

"Figure 1" below shows that the three highest contributors of $\mathrm{CO}_{2}$ in 2004 are energy industries, road transport and other industries which all share a huge amount of $153.0 \mathrm{~m}$ tonnes being measured. It must be noted that the 'Embodied Energy' carried by construction materials in the construction industry contributes heavily to the $\mathrm{CO}_{2}$ emissions being released in the environment.

\section{Figure 1}

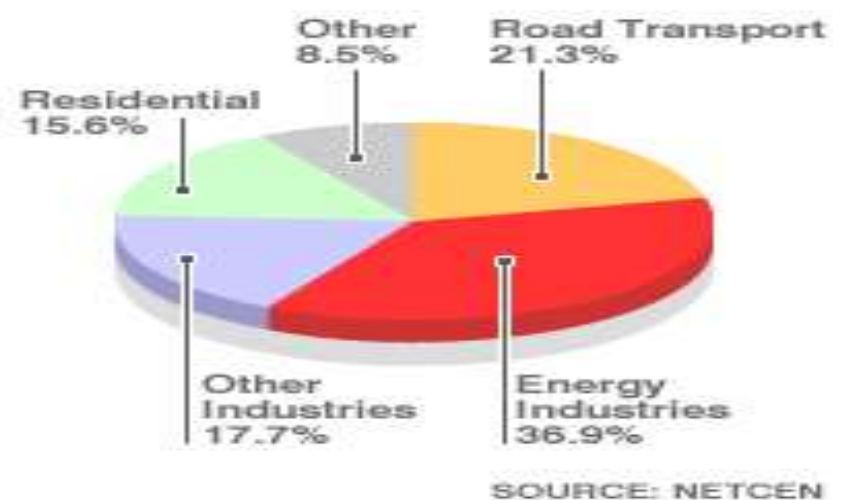

Though it may seem ominous and many people see climate change as being somewhat of a fearful reality, the signs are there and if nothing is going to be done know, the future generations are the one who would be made to suffer (Spiegel, R \& Meadows, 2007). 


\section{Conclusion}

In accordance with the efforts developed by Bangladesh, India and Australia, we may say that the growing awareness not only for carbon accounting but also the effect of climate change has brought about a drastic, rethink of the way buildings are now designed and run, and with the governments, initiatives to drastically lower greenhouse gas emissions, sustainability has taken a greater role in the built environment and of course to the country's GDP.

Edwards (2005, p. 19) recognises sustainable development as being “...development that meets the needs of the present without compromising the ability of future generations to meet their own needs." It further goes on to define sustainable design as creating "...buildings which are energy-efficient, healthy, comfortable, flexible in use and designed for long life" and found effective and efficient in improving the country's GDP.

Clients and contractors need to consider various issues to comply with current sustainable/green building design and construction principles as it affects the country's GDP, these may include:

- Conservation of energy and natural resources.

- Cost-efficiency (a pre-requisite for sustainability).

- Use of natural (passive) heating and cooling.

- Use of natural lighting (this may include energy saving and or healthy lighting).

- Design with nature and climate change in mined (Green Surroundings).

- Low maintenance (long life, robust design).

- Minimum site intervention and ecological foundations.

- Minimal use of construction materials and reduction of resource wastage.

- Reduction of Infrastructure, this may include lighting, roads and pipes.

- Use of 'Green' materials that are renewable and or biological materials and energy.

- Use of recycled materials and products that are safe to use.

- Elimination and or reduction of toxic materials and processes.

- Super insulation and ecological thermal energy storage.

- Use of vapour-diffusive-air and wind tight construction.

- Minimisation of electromagnetic fields.

- Adaptable, inclusive (access for all) design.

The information above, obtained from, RICS (2007, p. 16), highlights the various principles green and sustainable buildings are required to follow in order to obtain excellent BREEAM ratings which eventually determine whether a building is sustainable. The two principles amongst many which will reduce the effects of embodied energy are the use of recycled and renewable materials, this may include timber from sustainable forests.

RICS (2007, p. 14) states that:

"Green building, as a concept, is straightforward and makes perfect sense. It means making thoughtful design choices and using ecological materials in ways that create quality, long lasting environments with minimum damage to the planet."

The quote above shows the aim of sustainable and green buildings, which is to reduce the effect building materials and services, has on the environment.

The goal of "carbon accounting" is to help accurately predict the sustainability of any given building project and report the present carbon existing in the area. "Carbon accounting" tackles 4 major issues which when broken down make 22 performance indicators, the 4 major issues:

- Resource use impacts

- Environmental Impacts

- Social Impacts

- Economic Impacts

The information above obtained from, Edwards (2005, p. 117) states that:

"Resource use impacts, which include an assessment of the intrinsic and inherent values of the resources employed, especially their security, cost and environmental impacts. This allows decisions to be made between different construction materials (steel, concrete, glass), between different forms of capital (nature, social and intellectual)."

The quote highlights the relevance of embodied energy in construction materials in connection with the sustainability of a given building. 


\section{References}

[1] Pearce, D.W. (2003). "The Social Cost of Carbon and its Policy Implications", Oxford Review of Economic Policy.

[2] Tol, R.S.J. (2003). The Marginal Costs of Carbon Dioxide Emissions: An Assessment of the Uncertainties, Research Unit Sustainability and Global Change FNU-19, Centre for Marine and Climate Research, Hamburg University, Hamburg.

[3] Ali M. E. (2002). Transfer of Sustainable Energy Technology to developing countries as a means of reducing greenhouse gas emission - the case of Bangladesh: Review of relevant literature, Discussion Paper No. 02.08 edn. Department of Applied and International Economics, Massey University, New Zealand.

[4] Marland G., Fruit K., \& Sedjo R. (2001). Accounting for sequestered carbon: The question of permanence. Environmental Science \& Policy. 4: 259-268

[5] Johansen, B.E. (2002). The Global Warming Desk. Greenwood Press: Westport, CT. 236.

[6] Polglase, P.J. and Richards, G.P. (2002). Carbon sequestration and accounting in forests. Proceedings of Australian Forests Growers National Conference, Albany, Oct 2002. P.10

[7] Cline, W.R. (1992). The Economics of Global Warming. Institute for International Economics: Washington, DC.

[8] BBC News, (2007). Accessed: 16th November, 2012, Available at: < www.news.bbc.co.uk >

[9] Hall, K. (2006). The Green Building Bible, Volume 1. $3^{\text {rd }}$ ed. Green Building Press.

[10] Snell, C. \& Callahan, T. (2005). Building Green, A Complete How-To Guide To Alternative Building Methods. Lark Books, A Division of Sterling Publishing Co., Inc, New York.

[11] Bordass, W. (2001). Flying Blind: Things you wanted to know about Energy in Commercial Buildings but Were Afraid to Ask. The Association of the Conservation of Energy.

[12] Kilbert, J.C. (2007). The Next Generation of Sustainable Construction. Building Research \& Information, 35(6), pp. 595-601.

[13] Yamaguchi, K. Matsufuji, Y. \& Koyama, T. (2007). A New Structural System: Friction-Resistant Dry-Masonry. Building Research \& Information, 35(6), 616-628.

[14] McCann, J 2004. Clay and Cob Buildings. $3^{\text {rd }}$ Ed. A Shire Book.

[15] CIBSE (2007). CIBSE Release Sustainability Toolkit. Building Engineer, p. 43.

[16] Smith, P.F. (2006). Architecture in a Climate of Change. A Guide to Sustainable Design.

[17] Defra, (2009). Accessed: 11th November, 2012, Available at: < www.defra.gov.uk >

[18] Spiegel, R. \& Meadows, D. (2006). Green Building Materials, a Guide to Product Selection and Specification. $2^{\text {nd }}$ Ed.

[19] Edwards, B. (2005). A rough guide to sustainability. $2^{\text {nd }}$ Edition. RIBA enterprises. pp. 19-120.

[20] RICS, (2007). Code of Sustainable Homes. RICS Building Control, 2007, p. 7. 